\title{
Juvenile justice systems of care: results of a national survey of community supervision agencies and behavioral health providers on services provision and cross-system interactions
}

\author{
Christy K. Scott ${ }^{1 *}$ (D), Michael L. Dennis ${ }^{1}$, Christine E. Grella', Rodney R. Funk ${ }^{1}$ and Arthur J. Lurigio²
}

\begin{abstract}
Background: Youth involved in the juvenile justice $(\mathrm{J})$ system have high needs for behavioral health services, especially related to substance use and mental disorders. This study aimed to understand the extent to which elements in the cascade model of behavioral health services for JJ-involved youth are provided to youth by Community Supervision (CS) and/or Behavioral Health (BH) providers. In order to understand interactions across CS and $\mathrm{BH}$ systems, this study used a multistage probabilistic survey design to sample CS agencies and their primary $\mathrm{BH}$ service providers of substance use and mental health treatment in the United States. Parallel surveys were administered to both CS and BH providers regarding: characteristics of youth served, BH services available, whether services were provided directly and/or by referral, use of evidence-based practices (EBPs), and methods of collaboration, referral, and information exchange across CS and BH providers.

Results: The findings from weighted national estimates demonstrate that youth referred from CS to the BH programs represent a more severe sub-group of youth under CS supervision. There are established cross-system relationships for assessment and referral for substance use and mental health treatment, but less so for prevention services. Most CS programs refer youth to BH providers for these services, which typically utilize more highly trained staff to provide EBPs to a majority of the youth served. More intensive substance use and mental health treatment, aftercare, and recovery support services were limited in availability.

Conclusions: The findings suggest that although many elements in a cascade model of BH services for JJ-involved youth have been implemented within local systems of care through collaboration between CS and BH providers, there are several underdeveloped areas and potential for attrition across the service cascade. Greater attention to providing services to youth with higher levels of severity, aftercare services, and recovery support is warranted within a multi-systemic framework.
\end{abstract}

Keywords: Adolescents, Community supervision, Juvenile justice, Behavioral health, Substance use

\footnotetext{
* Correspondence: cscott@chestnut.org

'Chestnut Health Systems, 221 W. Walton St., Chicago, IL 60610, USA

Full list of author information is available at the end of the article
} International License (http://creativecommons.org/licenses/by/4.0/), which permits unrestricted use, distribution, and reproduction in any medium, provided you give appropriate credit to the original author(s) and the source, provide a link to the Creative Commons license, and indicate if changes were made. 
This article examines the types and extent of collaborations among community supervision (CS) and behavioral health $(\mathrm{BH})$ service providers to youth involved in the juvenile justice system (JJS) within local communitybased systems of care. Although CS is the most common dispositional alternative in the JJS (Kaeble \& Glaze, 2016), it is also one of the least studied in terms of its actual practices (Willison, Mears, Schollenberger, Owens, \& Butts, 2009). Community supervision is an umbrella term that includes court supervision, probation and parole (Champion, 2001); most CS agencies also manage youth who have been assigned deferred adjudication or diversion statuses. In addition, CS agencies set prevailing policies, enact supervisory protocols, and establish linkages with $\mathrm{BH}$ providers. As the central component of the JJS, it is important to understand the service needs of youth under CS and types of services provided to them to address their substance use and associated BH problems.

\section{Background}

\section{Behavioral health problems among youth in the JJS}

Youth involved in the JJS exhibit a higher prevalence of BH problems compared with their non-JJS-involved counterparts (Abram et al., 2003; Grisso, 2004). For example, in the United States, an estimated $45 \%$ to $65 \%$ of youth in the JJS meet criteria for having a substance use disorder (Dennis et al. 2009; Teplin et al. 2002; TimmonsMitchell et al. 1997). Teplin et al. (2002) conducted clinical assessments with a random sample of youth from the Cook County Juvenile Temporary Detention Center. Nearly two thirds of the males and three quarters of females met criteria for at least one psychiatric disorder; and approximately half of both males and females had a substance use disorder. Fewer than half of these adolescents receive any substance use services, and fewer than one-third of them are treated for a substance use disorder while on community supervision (e.g., juvenile probation and parole; Dennis et al. 2009; Shufelt \& Cocozza, 2006; Teplin et al. 2002; Wasserman et al. 2002).

In addition, JJS-involved youth typically report histories of trauma and victimization (Abram et al., 2004, 2007; Ford et al., 2013), childhood maltreatment (King et al., 2011), suicidality (Abram et al., 2008; Tapia et al., 2016; Teplin et al., 2015), and self-injury (Chapman \& Ford, 2008; Ford et al. 2010). JJS-involved youth are vulnerable to the human immunodeficiency virus (HIV) and other sexually transmitted infections (STIs) because of their risky sexual activities (Donenberg et al. 2015). The high rates of substance use and other psychiatric disorders among this population contribute to unhealthy sexual behaviors that further increase their risk of contracting HIV and other STIs (Teplin et al. 2003; Romero et al., 2007). Many JJ-involved youth also suffer from cognitive deficits and poor intellectual functioning, highlighting a need to design services for JJS-involved youth that take into consideration their intellectual challenges (Lansing et al. 2014). Comprehensive evidence-based services are essential to addressing criminogenic, health, and psychiatric needs, and ultimately altering trajectories of longterm criminal behavioral involvement and substance use and associated problems (Abram et al. 2015; D'Amico et al. 2008; Karnik et al., 2009; Epperson et al., 2011).

\section{Juvenile justice systems of care}

Given the high rates of co-occurrence between delinquency and other behavioral problems (Huizinga et al. 2000), JJ-involved youth frequently interact with multiple service systems, such as school-based services, substance use prevention and treatment, mental health, child welfare, and health services. Across these sectors, prevalence of substance use disorders is high, especially among youth in substance use, juvenile justice, and mental health systems (Aarons et al., 2001). Cross-system linkages are essential for screening, assessing, and referring youth to needed services, either within or across systems.

In recognition of the multi-varied needs of this population, recent policy initiatives have focused on improving community-based systems of care through juvenile-justice based partnerships (Cocozza et al.2010; Schubert \& Mulvey, 2014). Coordination of service delivery between CS and community-based $\mathrm{BH}$ service providers is essential to ensuring the delivery of needed services. Yet prior research has demonstrated that coordination between correctional agencies and treatment providers is often hindered by numerous organizational and programmatic barriers that impede cross-system communication, collaboration, and service delivery (Lehman et al. 2009; McCarty \& Chandler, 2009). Several mechanisms for facilitating coordination across service systems have been proposed, including information exchange, cross-agency client referrals, cross-system training of staff, networking protocols, interagency councils, and service integration models (Howell et al., 2004; Trupin \& Boesky, 1999).

This paper uses the Juvenile Justice Behavioral Health Services Cascade framework proposed by Belenko et al. (2017) as a framework for examining the systems of care for youth under CS and their corresponding BH service providers. This framework describes the various stages through which youth enter into the JJS system, are screened and assessed for treatment needs, referred to treatment/services, initiate treatment, and are engaged and retained in treatment/services over time. This sequential framework identifies transition points across the services cascade and service gaps that may be improved with greater cross-system coordination.

The JJS provides a wide range of opportunities for screening, assessing, treating, and referring large numbers 
of symptomatic youth who would otherwise have little or no access to $\mathrm{BH}$ care interventions (Ives et al. 2010). Moreover, the JJS is situated within the broader community system of care and provides opportunities for service integration across mental health, child protection, education, and juvenile justice agencies (Underwood \& Washington, 2016). Studies have demonstrated the feasibility of implementing evidence-based screening instruments, clinical assessment tools, and therapeutic interventions as well as the effectiveness of substance use and mental health treatments, and HIV-prevention services for young people within the JJS (Grisso \& Underwood, 2004; Tolou-Shams et al., 2009). Quality implementation of EBPs within JJ programs is associated with their effectiveness in reducing recidivism (Lipsey, 2009). Further, the availability of these services often fails to match the demand for care, and the rates of engagement and retention are correspondingly low (Mendel, 2011; Teplin et al., 2002; Young et al. 2007).

\section{Current Study}

In 2013, the National Institute on Drug Abuse, National Institutes of Health, responded to the challenges of JJS-involved youth by funding a multi-component initiative known as Juvenile Justice-Translational Research on Interventions for Adolescents in the Legal System (JJ-TRIALS), https://www.drugabuse.gov/jjtrials. The purpose of the current study within the JJ-TRIALS initiative was to develop a national profile of CS agencies and their corresponding $\mathrm{BH}$ agencies with respect to (1) the characteristics and $\mathrm{BH}$ needs of the youth they serve; (2) their practices related to $\mathrm{BH}$ screening, assessment, and referral in the areas of substance use and HIV prevention, and (3) their practices related to provision of substance use and mental health treatment. Within each area, the study also examined the use of evidence-based practices, information exchange, and referral practices.

In a multistage sample of counties, surveys were conducted with: 1) all CS agencies, 2) the primary BH service providers affiliated with each $C S$, and 3) the judge with the largest docket of youth on CS. The results of the survey of judges have been previously reported (Scott et al. 2017). This article combines the data from the $\mathrm{CS}$ agencies and primary $\mathrm{BH}$ service providers to represent the "juvenile justice (JJ) system of care" in order to examine the following questions:

(1) How do characteristics of youth on CS compare with youth served by their affiliated $\mathrm{BH}$ service providers?

(2) What is the availability and range of $\mathrm{BH}$ services for youth on CS that are provided directly and/ or by referral, and to what extent are these services either unavailable or unknown within the JJ systems of care?
(3) To what extent are EBPs for JJ-involved youth used within the local systems of care, what proportion of youth receive EBPs, and what are the qualifications of staff providing EBPs?

(4) How are patterns of information exchange, collaboration, and cross-system referral related to quality of $\mathrm{BH}$ services provided within JJ systems of care?

\section{Methods}

\section{Probability sampling}

Respondent selection was based on a three-stage national probability sampling process that included states, counties, and CS agencies within counties. States and counties were stratified by the number of youth aged 10 to 19 residing in them, as documented in the 2010 Current Population Survey (United States Census, 2012). In the first stage, the five largest states were selected with certainty, and the remaining 15 were selected with probabilities proportionate to the number of youth in five population strata to ensure that less-populated states were included in the study. In the second stage, within each state the largest county and any other megacounties (with 250,000 or more youth or half or more of the state's youth in smaller states) were selected with certainty. The remaining counties were selected with probabilities proportionate to the number of youth in those counties. In the two small sampled states where $\mathrm{CS}$ and $\mathrm{BH}$ services were organized by judicial district (vs. county), all counties in the state were selected with certainty. In stage 3, all CS agencies that served youth on CS in the 192 sampled counties were identified and surveyed regardless of the number of youth they served.

CS Agency Recruitment and Weighting. In states where there was direct management of CS agencies, we contacted key state-level stakeholders to identify and make a personal referral to the most appropriate CS agency contact in each county to encourage their participation in the survey. In states with decentralized systems, we identified and contacted a local leader (e.g., head of state sheriff or probation association) and asked them to do the same. In the 192 counties, 182 had one CS agency, and 10 had multiple CS agencies (9 had 2, and 1 had 3), for a total of 203 CS agencies. Surveys were completed by 195 of the 203 (96\%) CS agencies.

Data were weighted based on the inverse of the inclusion probability and were adjusted for nonresponses within states. The number of agencies overall and those providing a specific service were estimated by multiplying the weighted average number of agencies per county by the number of counties $(n=3143)$. For youth characteristics, the weight was further adjusted to account for the number of youth served so that the estimate better represented youth on CS $(N=770,323)$. 


\section{BH service provider recruitment and matching}

Each of the selected CS agencies was asked to identify the primary $\mathrm{BH}$ service providers of substance use and mental health treatment they used based on the number of youth under CS from their sampled county. This could be one or two providers and/or an internal unit of the CS agency. A total of $283 \mathrm{BH}$ providers were identified, and of these, 271 surveys (96\%) were completed and returned.

$\mathrm{BH}$ provider data was merged with the CS agency data at the CS agency level in the following way. Within counties, BH providers were matched with the CS agency that identified it as the main service providers for that agency. When there were multiple CS agencies per county (e.g., county and state-based CS), the identified $\mathrm{BH}$ providers were matched with their corresponding agencies. The same method was used when judicial districts were used within a state for CS agencies, instead of counties. If a single $\mathrm{BH}$ provider was identified by more than one CS agency within a county, that record was duplicated and matched to each CS agency. The average unweighted number of $\mathrm{BH}$ providers to $\mathrm{CS}$ agency is 1.4 and ranged from 0 to 2 ( 0 for 10 CS agencies). The $0 \mathrm{~s}$ included $6 \mathrm{CS}$ agencies that were themselves the primary (direct) $\mathrm{BH}$ service provider. For these cases, their responses to survey items were also used to represent the $\mathrm{BH}$ service provider.

In the cases $(n=86)$ where there were separate service providers of substance use and mental health treatment, their data was aggregated into a new $\mathrm{BH}$ service provider record. For dichotomous items (0/1 for no/yes), the max across $\mathrm{BH}$ providers was used to create the matching $\mathrm{BH}$ provider variable for that CS agency's record. For continuous items, such as the percentage of youth served, the average across $\mathrm{BH}$ agencies was used to create the new $\mathrm{BH}$ matched version of the variable. After aggregating the $\mathrm{BH}$ provider data to their corresponding CS agency, the final data set has $195 \mathrm{JJ}$ system-of-care records for the main analysis, which are then weighted to estimate the $3202 \mathrm{JJ}$ systems of care in the U.S.

The total number of $\mathrm{BH}$ service providers overall was estimated based on the weighted average number of $\mathrm{BH}$ service providers per county times the number of counties $(n=3143)$. The number of $\mathrm{BH}$ providers providing each specific service were estimated by multiplying the weighted average number of providers of each service times the number of $\mathrm{BH}$ service providers $(n=4252)$. For youth characteristics, the service provider weight was multiplied by the number of youth served to represent the estimated number $(n=548,613)$ of youth on CS seen by this primary $\mathrm{BH}$ service provider. Overall, data are weighted to reflect the national population estimate of the 4252 primary BH service providers and $3202 \mathrm{JJS}$
CS agencies in the 3143 counties in the United States, and have been adjusted for survey non-response at the state level.

\section{Survey domains and development}

The survey items were drawn largely from validated tools as well as studies, guidebooks, and compendiums that contained scientifically grounded information on the assessment of juvenile offenders. See Additional file 1 for a complete list of these sources.

A JJ-TRIALS survey advisory board of researchers, national association directors, juvenile justice researchers, and representatives from each of the JJ-TRIALS research centers met several times to review the study's survey, identify problem items, clarify definitions of terms, prioritize items for inclusion, and suggest overall revisions to item wording and sequencing. The penultimate instrument was sent to several CS agencies for pilot testing and further revision. The first dozen completed surveys were also reviewed very closely. Unclear answers to questions were clarified with respondents' input. Sources of confusion that stemmed from unclear words or instructions as well as ambiguous definitions of terms were removed from the instrument.

Lists of EBPs were based on the peer-reviewed programs enumerated in the federal National Registry of Evidence-Based Practices and Programs, and in Crime Solutions that were rated as having promising or strong evidence. Any practices rated as ineffective or harmful were included in the list of practices, but not in the measure of evidenced-based practice used by the agency. Other EBPs were identified and approved by members of the JJ-TRIALS cooperative. In each list of EBPs, respondents could also identify that they used locally developed measures (not counted as EBPs) as well as any "other evidence-based practices that they used for

." These responses were reviewed and coded by two investigators into "other EBP" or other categories of responses ("non-behavioral health EBP," "not an EBP," or "unknown"). The inter-rater rate of agreement was $70 \%$ with a Kappa of .62. The raters then reviewed and resolved any discrepancies.

The JJS CS and BH surveys each contained 13 sections that included questions on data availability; agency characteristics; youth characteristics; $\mathrm{BH}$ (substance use, HIV, and mental health) screening, clinical assessment and referral; substance use and HIV/STIrisk prevention; substance use and mental health treatment; and interagency collaborative activities, family engagement and technical assistance needs. The questions also focused on whether services were provided directly or through referrals; the names and utilization of EB tools, protocols, and other practices; and staff educational levels. 


\section{Item wording and formatting}

The survey included a variety of question types, including both "choose one" and "choose all that apply" from lists. These questions were always followed by an "other" response, allowing participants to write in more detailed or individualized information. Still other questions asked participants to respond numerically (e.g., number of staff, number of youth served) or to rate items using a Likert scale. Agency representatives were asked about the availability in their county of each service listed in Table 2. Specifically, they were asked to check all the following options that applied to each of the services:

- They don't know where youth can access the service in the county.

- The service is not available in the county.

- Their agency provides the service directly to youth, or

- The service is provided by an external agency.

If they provided the service directly, they were asked how many youth on CS received the service and what minimum level of staff education was required of the person administering the service. In describing their use of EBPs, respondents reviewed a list of EBPs for each type of service (prevention, substance use treatment, mental health treatment) and were asked to identify the practices they have implemented. Respondents were also asked to list any implemented practices that they developed on their own. A detailed list of the practices that were queried for each service area can be obtained from the first author.

\section{JJ system of care composite measures}

The following composite indices of cross-system interactions and collaboration were created.

(1) The CS to BH Referral Assertiveness items were collapsed across 14 referral activities CS agencies reported performing to facilitate referrals for substance use and/or mental health problems ( 1 if done with either or both types of providers, else 0 ). The scale score was the percentage of the 14 items endorsed, and demonstrated good internal consistency with a Cronbach's alpha of 0.79 .

(2) The CS Information Received from BH measure was the average of youth per CS agency the agency received information about from $\mathrm{BH}$ service providers. First, the average was calculated across 8 areas of information the CS agency received from substance use and mental health treatment providers. These include admission and discharge dates, discharge status and summary reports, monthly progress reports, dates of missed appointments, results of urine or other biological tests, and the amount of services received. The alpha across these eight items was high, at 0.98 .

(3) The CS Quality of Direct BH Services measure is based on the count of: 1) whether a CS agency directly provides a service, 2 ) if that service is evidence-based, 3 ) is the evidence-based service provided to $50 \%$ or more of the youth served, and 4) is there an educational requirement of at least a bachelor's or nursing degree for those implementing the service. This count goes across all services: screening, clinical assessment, substance use prevention, HIV risk behavior prevention, substance use treatment, and mental health treatment. Altogether, there were 24 items with an alpha of 0.88 .

(4) The BH Information Sent to CS measure is an average per agency across 8 items that ascertain the percentage of youth for which the CS agency received information from the $\mathrm{BH}$ agencies. Again, there was high internal consistency, with an alpha of 0.96 .

(5) The Quality of BH Direct BH Services is calculated in the same manner as no. 3 , with regard to $\mathrm{BH}$ services provided by the $\mathrm{BH}$ provider. For these 24 items, the alpha was 0.75 .

(6) The CS to BH Collaboration Scale is based on 11 activities the CS agency reported doing with external BH agencies to help facilitate services to youth on CS. Items were collapsed across both substance use and mental health items by taking the max ( 1 if done with either or both types of providers, else 0 ). The scale score was the percentage of the 11 activities endorsed and had an alpha of 0.79 .

(7) The BH to CS Collaboration Scale is calculated in the same manner as no. 6 above with regard to 11 activities, except from the perspective of the $\mathrm{BH}$ provider with regard to their collaborative activities with CS agencies. For these 11 items, the alpha was 0.81 .

The two collaboration measures above (nos. 6 and 7) were correlated $(r=0.51)$ but measured different functions. They were dichotomized into low and high groups based on median splits. These two dichotomies were then used to create four separate groups based on CS low/high on collaboration and the $\mathrm{BH}$ low/high on collaboration. These four groups include: (1) CS Low/BH Low $(n=1229)$, (2) CS High/CS Low $(n=666)$, (3) CS Low/BH High $(n=536)$, and (4) CS High/BH High $(N=771)$. Differences across these groups on each scale were examined by $\mathrm{F}$ test, effect 
size using the f-index $[$ small $=0.10$, moderate $=0.25$, large $=0.40]$ (Cronbach, 1960), and percentage of variance explained using eta-square.

\section{Survey administration}

All of the CS agencies in the sampled counties were contacted to participate in the survey. The breadth of the CS survey often required input from diverse agency staff with access to different information. To identify the most appropriate staff member for completing the survey, each state was assigned a survey coach who contacted each agency's key stakeholder and provided an overview of the survey components. During this phone conference, the survey coach and stakeholder identified the best respondent for answering each set of questions and the best available data sources for completing particular survey items. A similar process was used for the $\mathrm{BH}$ agencies, in which the survey coach contacted the CS provider's key BH stakeholder, provided an overview of the survey components, and identified the best respondent for answering each set of questions and the best available data sources for completing particular survey items.

A survey coach then delivered a PowerPoint presentation to the potential respondents which described the survey's goals and data-collection process. In addition, the survey coaches mailed the surveys and made surveyorientation calls to all respondents who had agreed to participate in the study. At the end of these calls, the coaches and respondents agreed on a completion date for the survey. Coaches also contacted respondents each week to answer any questions and to obtain updates on the progress of the surveys.

Upon receipt of completed surveys, survey coaches reviewed the surveys, and respondents were queried about missing data, inconsistent responses, or notes from participants with questions about the items. Surveys were rekeyed to reach at least $99 \%$ intra-survey agreement, and 1 in 6 was rekeyed. The rekey agreement rate was $98.9 \%$ for the CS agency surveys and $99.0 \%$ for the BH survey provider surveys. The surveys were reviewed a final time by the lead analyst to remove or resolve any remaining inconsistencies. The Cronbach's Alpha for 16 of the 17 survey sections that consisted of correlated items was .7 or higher ( 5 at $.9+, 8$ at .8 to .89 , and 3 at 7 to .79), with one section (Family Systems Engagement) attaining an Alpha $=.67$.

\section{Analytic methods}

Data were analyzed with IBM's Statistical Package for Social Sciences (SPSS) Version 25 frequencies and descriptive procedures, using the national weights described above for agencies (inverse of state selection, county selection, and adjustment for non-response) and youth (agency weight times the estimated number of youth served). Descriptive data presented in Tables 1, 2 and 3 show prevalence and estimated sample size, which is based on the prevalence multiplied by the number of estimated agencies. Differences between prevalence estimates were evaluated using odds ratios (OR). The denominator for a sample subset is presented in the table notes. The figures are all weighted as well. SPSS multivariate Generalized Linear Model (GLM) was used to test differences on each scale based on the four collaboration groups formed by crossing the two median split variables described above, specifically: (1) CS Low/BH Low $(n=1229),(2)$ CS High/CS Low $(n=666)$, (3) CS Low/BH High $(n=536)$, and (4) CS High/BH High $(N=771)$. Results of these multivariate analyses, presented in Table 4, report the means of each scale by the four groups, the F- statistic, $p$-value, and eta-square. Effect size is evaluated using the findex (which we have interpreted as $0.10=$ small, $0.25=$ moderate, and $0.40=$ large) reported in Table 4 . To avoid inflating the power of this analysis, the weighted n's were reduced to maintain the weighted proportions, but add up to the raw $\mathrm{n}$ of observations.

\section{Results \\ CS agency characteristics}

Of the 3202 CS agencies in the United States, 27\% operate under a state judicial branch; 39\% under a state executive branch; $25 \%$ under a county, municipal, or local judicial branch; $6 \%$ under a municipal or local executive branch; and 3\% under other authorities. Approximately $32 \%$ had a specialty court, with the most common being a juvenile drug treatment court (12\%), family drug treatment court (6\%), peer court (5\%), teen court $(4 \%)$, or mental health court (2\%). In terms of the legal minimum age of youth that CS agencies could supervise, $42 \%$ specified no lower age limit, $22 \%$ specified nine years or younger, $20 \%$ specified 10 or 11 years, and $17 \%$ specified 12 or 13 years. Regarding the legal maximum age of youth that CS agencies could supervise, 5\% specified 14 to 16 years, $38 \%$ specified 17 years, $25 \%$ specified 18 to 20 years, $24 \%$ specified 21 years or older, and $8 \%$ specified no upper age limit.

\section{CS employees and their educational level}

The average CS agency employed a staff of 10 full-time equivalents (FTEs) working with an average of 240 youth on CS. Approximately $55 \%$ of all youth were seen in a subset of 18 CS agencies that were larger, averaging 200 FTEs working with an average of 4406 youth on CS. Almost all (92\%) of the CS agencies employed non-clinical staff, and almost a fourth (22\%) employed master's-level clinicians in order to serve youth on CS. Other staff 
Table 1 Data Availability and Rates of Youth Characteristics by Type of Providerla

\begin{tabular}{|c|c|c|c|c|}
\hline \multirow[b]{2}{*}{ Youth Characteristic } & \multicolumn{2}{|c|}{ Community Supervision Providers } & \multicolumn{2}{|c|}{ Behavioral Health Providers } \\
\hline & Data Available & Prevalence & Data Available & Prevalence \\
\hline \multicolumn{5}{|l|}{ Demographics } \\
\hline Male & $84 \%$ & $73 \%$ & $80 \%$ & $67 \%$ \\
\hline Female & $84 \%$ & $27 \%$ & $80 \%$ & $33 \%$ \\
\hline Under age 14 & $76 \%$ & $12 \%$ & $77 \%$ & $18 \%$ \\
\hline Age 14-15 & $79 \%$ & $36 \%$ & $77 \%$ & $27 \%$ \\
\hline Age 16-17 & $79 \%$ & $44 \%$ & $77 \%$ & $39 \%$ \\
\hline 18 or older & $81 \%$ & $8 \%$ & $78 \%$ & $12 \%$ \\
\hline White/Caucasian & $81 \%$ & $53 \%$ & $77 \%$ & $50 \%$ \\
\hline Black/African American & $80 \%$ & $26 \%$ & $77 \%$ & $19 \%$ \\
\hline Other or Mixed Race/Unknown & $70 \%$ & $6 \%$ & $75 \%$ & $16 \%$ \\
\hline Hispanic/Latino Ethnicity & $79 \%$ & $18 \%$ & $77 \%$ & $21 \%$ \\
\hline \multicolumn{5}{|l|}{ Substance Use Problems } \\
\hline Any substance use problems including alcohol & $46 \%$ & $51 \%$ & $71 \%$ & $66 \%$ \\
\hline Marijuana use problems & $35 \%$ & $49 \%$ & $65 \%$ & $59 \%$ \\
\hline Alcohol use problems & $40 \%$ & $25 \%$ & $66 \%$ & $41 \%$ \\
\hline Prescription drug misuse & $25 \%$ & $19 \%$ & $50 \%$ & $16 \%$ \\
\hline $\begin{array}{l}\text { Other drug use problems (e.g., amphetamine/methamphetamine, cocaine/crack, } \\
\text { opioids/heroin, hallucinogens/K2/Salts) }\end{array}$ & $35 \%$ & $18 \%$ & $53 \%$ & $18 \%$ \\
\hline Tobacco use problems & $24 \%$ & $32 \%$ & $48 \%$ & $51 \%$ \\
\hline \multicolumn{5}{|l|}{ Mental Health Problems } \\
\hline $\begin{array}{l}\text { Serious Family Problems (e.g., substance use, serious mental illness, domestic } \\
\text { violence, incapacitating chronic illness) }\end{array}$ & $31 \%$ & $60 \%$ & $58 \%$ & $67 \%$ \\
\hline $\begin{array}{l}\text { Internalizing Mental Disorders (e.g., Mood, Depression, Anxiety, Trauma, } \\
\text { Posttraumatic Stress Disorder, Psychosis) }\end{array}$ & $30 \%$ & $35 \%$ & $70 \%$ & $57 \%$ \\
\hline $\begin{array}{l}\text { Externalizing Mental Disorders (e.g., Attention deficit, hyperactivity, conduct, } \\
\text { pathological gambling, or other impulse control disorder) }\end{array}$ & $26 \%$ & $35 \%$ & $67 \%$ & $52 \%$ \\
\hline Learning Disabilities or Other Cognitive Impairment & $25 \%$ & $28 \%$ & $47 \%$ & $28 \%$ \\
\hline Suicide Risk (e.g., self-mutilation, thoughts, plans, means, attempts) & $31 \%$ & $13 \%$ & $56 \%$ & $22 \%$ \\
\hline \multicolumn{5}{|l|}{ Other Behavioral Health Problems } \\
\hline $\begin{array}{l}\text { Risky sexual activity (e.g., unprotected sex, sex under the influence, multiple } \\
\text { sex partners, sex trading, sex with high risk partners) }\end{array}$ & $17 \%$ & $51 \%$ & $39 \%$ & $44 \%$ \\
\hline Physical, Sexual or Emotional Victimization & $29 \%$ & $39 \%$ & $57 \%$ & $44 \%$ \\
\hline Violence towards other & $32 \%$ & $25 \%$ & $46 \%$ & $36 \%$ \\
\hline Physical Health Problems & $21 \%$ & $11 \%$ & $56 \%$ & $12 \%$ \\
\hline $\begin{array}{l}\text { Needle related risk activity (e.g., use, old or unclean needles, sharing, sharing } \\
\text { with risky partners) }\end{array}$ & $14 \%$ & $2 \%$ & $40 \%$ & $3 \%$ \\
\hline
\end{tabular}

la Data are weighted to reflect the estimated national population estimate of the $3202 \mathrm{CS}$ agencies and $4252 \mathrm{BH}$ service providers and in the U.S. and have been adjusted for survey non-response at the state level

positions included bachelor's-level clinicians (19\%) and registered nurses $(6 \%)$.

\section{BH service provider characteristics Accreditation and funding sources}

Nationally there were 4252 primary BH service providers for youth on CS. Of these, $65 \%$ operated under the auspices of private non-profit organizations, $20 \%$ under private for-profit organizations, 9\% under county or other local government agencies, and $1 \%$ under state government agencies. Slightly more than half of the service providers $(52 \%)$ reported being accredited by a state mental health department, nearly half ( $47 \%$ ) by a state substance use department, and $41 \%$ by the Commission on Accreditation of Rehabilitation Facilities (CARF). Other accreditation bodies included the State Department of Health (27\%), the Joint Commission (11\%), the Council on Accreditation (3\%), and a hospital licensing authority (1\%). 
Table 2 Availability and Mode of Provision of Behavioral Health Services for Juvenile Offenders $\backslash a$

\begin{tabular}{|c|c|c|c|c|}
\hline Service & CS Directly Provides & BH Directly Provides & External Provider/Other & $\begin{array}{l}\text { Not Available, } \\
\text { Don't Know }\end{array}$ \\
\hline \multicolumn{5}{|l|}{ Prevention } \\
\hline Substance Use Prevention & $17 \%$ & $55 \%$ & $39 \%$ & $1 \%$ \\
\hline HIV/AIDS testing & $0 \%$ & $4 \%$ & $94 \%$ & $2 \%$ \\
\hline Tuberculosis, Hepatitis B, Hepatitis C testing & $1 \%$ & $4 \%$ & $93 \%$ & $3 \%$ \\
\hline Sexually transmitted infection (STI) testing & $0 \%$ & $3 \%$ & $94 \%$ & $3 \%$ \\
\hline STI prevention, education and counseling & $2 \%$ & $23 \%$ & $73 \%$ & $3 \%$ \\
\hline Hepatitis prevention, education, and counseling & $0 \%$ & $22 \%$ & $75 \%$ & $4 \%$ \\
\hline HIV prevention, education and counseling & $2 \%$ & $25 \%$ & $64 \%$ & $9 \%$ \\
\hline \multicolumn{5}{|l|}{ Substance Use Treatment } \\
\hline Outpatient & $9 \%$ & $93 \%$ & $6 \%$ & $1 \%$ \\
\hline Co-occurring substance and mental health treatment & $5 \%$ & $80 \%$ & $17 \%$ & $3 \%$ \\
\hline Continuing or aftercare & $4 \%$ & $68 \%$ & $25 \%$ & $10 \%$ \\
\hline Intensive outpatient & $1 \%$ & $39 \%$ & $48 \%$ & $15 \%$ \\
\hline Other recovery support & $1 \%$ & $25 \%$ & $55 \%$ & $21 \%$ \\
\hline Residential treatment & $1 \%$ & $10 \%$ & $65 \%$ & $25 \%$ \\
\hline Medication assisted treatment & $0 \%$ & $7 \%$ & $62 \%$ & $31 \%$ \\
\hline Detoxification & $0 \%$ & $4 \%$ & $57 \%$ & $39 \%$ \\
\hline \multicolumn{5}{|l|}{ Mental Health Treatment } \\
\hline Individual counseling & $9 \%$ & $91 \%$ & $10 \%$ & $0 \%$ \\
\hline Family counseling & $11 \%$ & $87 \%$ & $14 \%$ & $0 \%$ \\
\hline Group counseling & $4 \%$ & $76 \%$ & $24 \%$ & $2 \%$ \\
\hline Medication assisted treatment & $1 \%$ & $74 \%$ & $29 \%$ & $0 \%$ \\
\hline Residential treatment & $1 \%$ & $7 \%$ & $76 \%$ & $18 \%$ \\
\hline Day program & $<1 \%$ & $18 \%$ & $64 \%$ & $19 \%$ \\
\hline
\end{tabular}

la Data are weighted to reflect the estimated national population estimate of the 3202 CS agencies and 4252 BH service providers and in the U.S. and have been adjusted for survey non-response at the state level

Service providers received funding from a variety of sources including: self-paying clients (75\%); private insurance (74\%); state (69\%), county (48\%), and federal governments (39\%); private donations (24\%); and local (municipal) government entities (8\%). Approximately $2 \%$ were a $\mathrm{BH}$ service unit within a CS agency.

\section{BH employees and their educational level}

The average BH service provider employed a staff of 15 FTEs working with an average of 174 youth on CS. Half of all youth were seen in a subset of $33(0.8 \%)$ BH providers that were larger, averaging 98 FTEs working with an average of 2664 youth on CS. Almost all (93\%) of the BH providers employed master's-level clinicians, and three-fourths $(76 \%)$ employed non-clinical staff in order to serve youth on CS. Other staff positions included psychiatrists (54\%), bachelor's-level clinicians (54\%), registered nurses (45\%), doctoral-level clinicians (36\%), non-degreed clinical staff (31\%), physician's assistants (19\%), and physicians (5\%).

\section{Characteristics and needs of youth served within JJ systems of care}

Table 1 presents the percentages of CS agencies and the corresponding $\mathrm{BH}$ providers with data available on and prevalence of youth demographic characteristics and their substance use, mental health, and other $\mathrm{BH}$ problems. Estimates were adjusted for nonresponse/data unavailability and the number of youth served by each agency; thus, the estimates represent the 770,323 youth on CS in the United States. It is important to note that the JJ-involved youth referred from $\mathrm{CS}$ to $\mathrm{BH}$ providers are a subset of all youth who are under CS. As such, we expected the characteristics of youth served to be generally similar across the two systems, although skewed toward higher severity of $\mathrm{BH}$ problems among youth who are referred into $\mathrm{BH}$ programs. Because the youth served in the $\mathrm{CS}$ and $\mathrm{BH}$ systems are not independent, statistical tests of differences are not conducted; however, we note below variables on which there was a deviation 
Table 3 Service Provision and Use of Evidence-Based Practices by Type of Providerla

\begin{tabular}{|c|c|c|c|c|c|}
\hline & \multicolumn{2}{|c|}{$\begin{array}{l}\text { National Estimate of Community } \\
\text { Supervision Agencies Providing }\end{array}$} & \multicolumn{3}{|c|}{ Row \% of Agencies Providing } \\
\hline & $\begin{array}{l}\text { No. of CS } \\
\text { Agencies }\end{array}$ & $\begin{array}{l}\% \text { of all } \\
\text { Providers }\end{array}$ & $\begin{array}{l}\text { Used } \\
\text { EBP }\end{array}$ & $\begin{array}{l}\text { Used EBP on } 50 \% \text { or } \\
\text { more of youth }\end{array}$ & $\begin{array}{l}\text { Provided by clinical staff with } \\
\text { Bachelor's degree or above }\end{array}$ \\
\hline Screening & 2034 & $64 \%$ & $86 \%$ & $78 \%$ & $29 \%$ \\
\hline Clinical Assessment & 772 & $24 \%$ & $98 \%$ & $49 \%$ & $84 \%$ \\
\hline Substance Use Prevention & 544 & $17 \%$ & $48 \%$ & $15 \%$ & $92 \%$ \\
\hline HIV Testing and Prevention & 96 & $3 \%$ & $<1 \%$ & $<1 \%$ & $86 \%$ \\
\hline Substance Use Treatment & 365 & $11 \%$ & $95 \%$ & $33 \%$ & $90 \%$ \\
\hline Mental Health Treatment & 431 & $13 \%$ & $86 \%$ & $18 \%$ & $100 \%$ \\
\hline \multirow{3}{*}{$\begin{array}{l}\text { Both Substance Use and Mental Health } \\
\text { Treatment }\end{array}$} & 253 & $8 \%$ & $86 \%$ & $37 \%$ & $100 \%$ \\
\hline & \multicolumn{2}{|c|}{$\begin{array}{l}\text { National Estimate of Behavioral } \\
\text { Health Agencies Providing }\end{array}$} & \multicolumn{3}{|c|}{ Row $\%$ of Agencies Providing } \\
\hline & $\begin{array}{l}\text { No. of } \mathrm{BH} \\
\text { Agencies }\end{array}$ & $\begin{array}{l}\% \text { of all } \\
\text { Providers }\end{array}$ & $\begin{array}{l}\text { Used } \\
\text { EBP }\end{array}$ & $\begin{array}{l}\text { Used EBP on } 50 \% \text { or } \\
\text { more of youth }\end{array}$ & $\begin{array}{l}\text { Provided by clinical staff with } \\
\text { Bachelor's degree or above }\end{array}$ \\
\hline Screening & 2503 & $78 \%$ & $95 \%$ & $90 \%$ & $96 \%$ \\
\hline Clinical Assessment & 3107 & $97 \%$ & $86 \%$ & $85 \%$ & $98 \%$ \\
\hline Substance Use Prevention & 1790 & $56 \%$ & $39 \%$ & $6 \%$ & $80 \%$ \\
\hline HIV Testing and Prevention & 853 & $27 \%$ & $18 \%$ & $7 \%$ & $96 \%$ \\
\hline Substance Use Treatment & 3096 & $97 \%$ & $90 \%$ & $90 \%$ & $97 \%$ \\
\hline Mental Health Treatment & 2966 & $93 \%$ & $98 \%$ & $73 \%$ & $100 \%$ \\
\hline $\begin{array}{l}\text { Both Substance Use and Mental Health } \\
\text { Treatment }\end{array}$ & 2622 & $82 \%$ & $98 \%$ & $92 \%$ & $100 \%$ \\
\hline
\end{tabular}

la Data are weighted to reflect the estimated national population estimate of the $3202 \mathrm{CS}$ agencies and $4252 \mathrm{BH}$ service providers and in the U.S. and have been adjusted for survey non-response at the state level

Table 4 Mean of Collaboration Measures by CS and BH Collaboration Groups

\begin{tabular}{|c|c|c|c|c|c|c|c|c|c|}
\hline & \multicolumn{9}{|c|}{ Collaboration groups based on low (0-0.36) and high $(0.37+)$} \\
\hline & Total & CS Low/ BH Low & CS High/ BH Low & CS Low/ BH High & CS High/ BH High & $F$ & $p$ & f-index & eta-sq. \\
\hline Unweighted n & 185 & 33 & 40 & 28 & 84 & & & & \\
\hline Weighted n & 3202 & 1229 & 666 & 536 & 771 & & & & \\
\hline Weighted \% & $100 \%$ & $38 \%$ & $21 \%$ & $17 \%$ & $24 \%$ & & & & \\
\hline Weight Adjusted $n$ & 185 & 71 & 38 & 31 & 45 & & & & \\
\hline $\begin{array}{l}\text { CS to BH Referral assertiveness } \\
\text { (\% of } 14 \text { items) }\end{array}$ & $63 \%$ & $53 \%$ & $76 \%$ & $60 \%$ & $72 \%$ & 19.08 & 0.000 & 0.57 & 0.25 \\
\hline $\begin{array}{l}\text { CS Information received from BH } \\
\text { (\% of } 8 \text { items) }\end{array}$ & $49 \%$ & $53 \%$ & $48 \%$ & $23 \%$ & $65 \%$ & 7.71 & 0.000 & 0.36 & 0.12 \\
\hline $\begin{array}{l}\text { CS Quality of direct BH services } \\
\text { (\% of } 24 \text { items) }\end{array}$ & $11 \%$ & $9 \%$ & $13 \%$ & $11 \%$ & $14 \%$ & 1.40 & 0.246 & 0.15 & 0.02 \\
\hline $\begin{array}{l}\text { BH Information sent to CS } \\
\text { (\% of } 8 \text { items) }\end{array}$ & $52 \%$ & $45 \%$ & $54 \%$ & $52 \%$ & $64 \%$ & 2.33 & 0.076 & 0.20 & 0.04 \\
\hline $\begin{array}{l}\text { BH Quality of direct BH services } \\
\text { (\% of } 24 \text { items) }\end{array}$ & $60 \%$ & $59 \%$ & $58 \%$ & $64 \%$ & $63 \%$ & 1.01 & 0.389 & 0.13 & 0.02 \\
\hline Average across above & $47 \%$ & $44 \%$ & $50 \%$ & $42 \%$ & $55 \%$ & & & & \\
\hline
\end{tabular}

The 4 groups explain 39\% of the variance in the joint distribution of these measures of collaboration (1-Wilk's lambda)

Effect size $f$-index: small $=0.10$, moderate $=0.25$ and large $=0.40$

$\mathrm{CS}=$ community supervision; $\mathrm{BH}=$ behavioral health

Bold indicates $p<.001$, f-index $>0.10$, eta-sq $>.01$ 
of approximately $10 \%$ between CS and $\mathrm{BH}$ prevalence estimates or ORs of $\geq 2.0$.

\section{Demographic characteristics}

Between $70 \%$ and $84 \%$ of the CS agencies and $75 \%-80 \%$ of the $\mathrm{BH}$ providers had data available for youth demographic characteristics. Most youth were male (73\%), Caucasian/White (53\%), and between the ages of 14 and 17 (80\%). Based on the 2010 US Current Population Survey, the proportions of youth identified as Black/African American (26\%) or other/mixed race (6\%) were higher than those identified in the general population. The proportion of Hispanic/Latino (18\%) youth was similar to the proportion in the general population. Relative to all youth seen by CS agencies, those seen by $\mathrm{BH}$ service providers were less likely to be aged $14-15$ (36\% vs. $27 \%$, $\mathrm{OR}=0.65$ ); youth in the $\mathrm{BH}$ providers were also more likely to be of other or unknown/mixed race relative to those in CS programs $(16 \%$ vs. $6 \%, \mathrm{OR}=2.94)$.

\section{Substance use problems}

Between $24 \%$ and $46 \%$ of the CS agencies and $48 \%$ and $71 \%$ of the $\mathrm{BH}$ providers had data available on substance use problems. Relative to all youth seen by CS agencies, estimates of prevalence of substance use problems for youth seen by $\mathrm{BH}$ service providers were consistently higher, including for any substance use problem $(51 \%$ vs. $66 \%$, OR $=1.90)$, marijuana problems $(49 \%$ vs. $59 \%$, OR = $1.47)$, alcohol problems $(25 \%$ vs. $41 \%, \mathrm{OR}=2.06)$, and tobacco problems $(32 \%$ vs. $51 \%$, OR $=2.25)$. Estimates of misuse of prescription drugs $(19 \%, 16 \%)$ and other substance use (18\%) were similar.

\section{Mental health}

Between $25 \%$ and $31 \%$ of the CS agencies and $47 \%$ and $70 \%$ of the $\mathrm{BH}$ providers had data available on youth mental health needs. Relative to all youth seen in CS, the subset of youth seen by $\mathrm{BH}$ service providers had higher levels of mental health problems, including for internalizing disorders $(57 \%$ vs. $35 \%, \mathrm{OR}=2.42)$, externalizing disorders $(52 \%$ vs. $35 \%$, OR $=2.05)$, and suicide risk $(22 \%$ vs. $13 \%, \mathrm{OR}=1.88)$. Estimates for serious family problems $(60 \%, 67 \%)$ and for learning disabilities and other cognitive impairments $(28 \%)$ were similar.

\section{Other behavioral health problems}

Between 14\% and 32\% of the CS agencies and 39\% and $57 \%$ of the $\mathrm{BH}$ agencies had data available on other $\mathrm{BH}$ problems. Relative to all youth seen in CS, the subset of youth seen by $\mathrm{BH}$ service providers reported significantly higher rates of violence toward others $(25 \%$ vs. $36 \%$, OR $=1.72$ ). Estimates of risky sexual behaviors (44\%, 51\%), physical, sexual, or emotional victimization (39\%, 44\%), physical health problems $(11,12 \%)$, and or needle-risk behaviors $(2 \%, 3 \%)$ were similar across CS and $\mathrm{BH}$ providers.

\section{Patterns of service delivery and availability within $\mathrm{JJ}$ systems of care}

Figure 1 shows the percentage of CS programs that directly provide six types of $\mathrm{BH}$ services as well as referrals for youth to external providers for these services. Although nearly two thirds of CS agencies (64\%) directly screened youth for various $\mathrm{BH}$ problems, an overlapping $64 \%$ referred youth to other agencies for $\mathrm{BH}$ screening as well. In contrast, few of the CS agencies directly provided additional screening, clinical assessment, substance use prevention, HIV prevention and testing, substance use treatment, and mental health treatment.

The next set of analyses examines the service delivery pattern complexity of the JJ systems of care. The first 3 columns of Table 2 show the percentages of times each service was provided directly by the CS agency, the $\mathrm{BH}$ service provider, or another agency (e.g., public health department). The last column is the combined percent of times when both the CS agency and/or BH service provider indicated that the service was not available in the county or that they did not know about its availability.

\section{Prevention services}

Few CS or BH programs directly provided prevention services, with the exception of substance use prevention, which was provided by $55 \%$ of the BH service providers and $17 \%$ of the CS agencies. Youth were referred to other providers for substance use prevention (i.e., no direct provision in either $\mathrm{CS}$ or affiliated $\mathrm{BH}$ programs) among $39 \%$ of the respondents.

Few CS agencies directly provided testing, prevention, education, or counseling for HIV, other STIs, or infectious diseases. About one-quarter (23\%) of the $\mathrm{BH}$ service providers provided infectious disease prevention, education, and counseling (but not testing). A majority of the CS and affiliated $\mathrm{BH}$ providers referred youth to external providers for these services; less than 10\% reported that these services were either unavailable in the county or did not know where the services could be found.

\section{Substance use treatment}

Overall, $11 \%$ of CS agencies and $97 \%$ of the affiliated BH programs directly provided some form of substance use treatment. The most common form of substance use treatment by $\mathrm{BH}$ providers was outpatient ( $93 \%$ of $\mathrm{BH})$. A large proportion of the $\mathrm{BH}$ providers $(80 \%)$ provided treatment for co-occurring substance use and mental health disorders, whereas $17 \%$ of the affiliated CS and BH providers referred youth to other providers for co-occurring disorder treatment. Close to two fifths of the $\mathrm{BH}$ providers directly provided intensive outpatient treatment, and close to half 


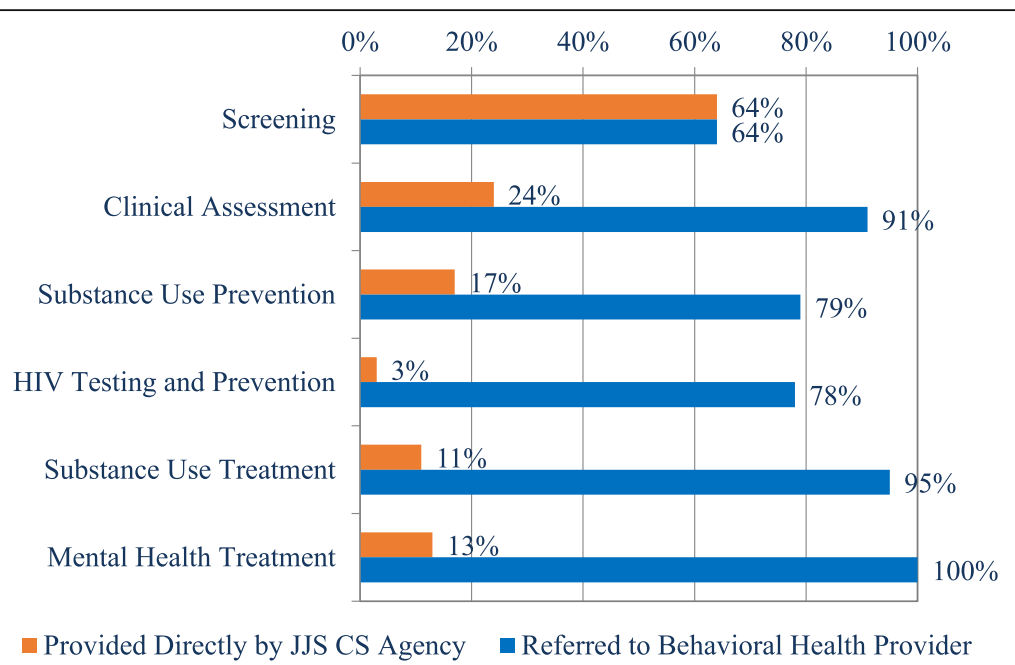

Fig. 1 Services provided to youth in juvenile justice system directly or through referral (weighted percentage of $3202 \mathrm{JJ}$ community supervision agencies). Orange bar = Provided Directly by a JJS CS Agency; blue bar = Referred to Behavioral Health Provider

(48\%) of the affiliated CS and BH providers did so through external referral. Few $\mathrm{BH}$ providers $(7 \%)$ offered medication-assisted treatment, although it was often provided through external referrals (62\%). Residential treatment and other recovery support services were most frequently provided through external referrals (65\% and 55\%, respectively). A substantial portion of the affiliated providers indicated that the following services were either non-existent in the county or unknown to them: recovery support services $(21 \%)$, residential treatment (25\%), medication-assisted treatment (31\%), and detoxification (39\%).

\section{Mental health treatment}

Overall, 13\% of CS agencies and 93\% of BH agencies directly provided some form of mental health treatment. Most common among CS agencies was provision of individual (9\%) and family counseling (11\%); less than 5\% provided other forms of mental health treatment. Instead, a majority of the affiliated $\mathrm{BH}$ programs directly provided counseling services, including individual (91\%), family (87\%), and group (76\%), as well as medication (74\%); youth were less often referred to external providers for counseling or medication services. Fewer BH programs provided day treatment programs $(18 \%)$ or residential treatment $(7 \%)$, while a majority of the affiliated CS and BH providers indicated these more intensive mental health services were provided through external referral $(64 \%, 76 \%$, respectively). However, approximately one fifth $(18 \%, 19 \%)$ indicated that these services were either not available in the county or they did not know if they were available.

\section{Use of EBPs}

Data on the provision of EBPs by CS providers are shown in the top half of Table 3 and for BH providers in the bottom half. The first two columns show the weighted subset of agencies providing each type of $\mathrm{BH}$ service. The next three columns show the weighted percentages of the subset that reported using one or more EBPs, implementing these EBPs with at least one half of the youth in their programs, and delivery of EBPs by clinical staff who held bachelor's degrees, registered nurse qualifications, or higher degrees.

\section{Community supervision agencies}

Although direct provision of services is generally low among CS agencies (with the exception of screening), among those CS agencies that reported providing screening, assessment, and $\mathrm{BH}$ treatment, most $(>85 \%)$ used EBPs. Less than one-third (32\%) of CS agencies that provided substance use prevention services used EBPs, and virtually none used EBPs for HIV testing and prevention. Although a majority of CS agencies provided screening, and most of these (78\%) used EPPs with at least half of the youth, few (29\%) reported using clinical staff with bachelor's, nursing, or higher-level degrees. In contrast, less than one-quarter of the CS agencies provided in-depth assessment, prevention, or treatment services; among those that provided these services, most used EBPs, although less than half did so with $50 \%$ or more of the youth in their programs. Most CS agencies that used EBPs reported employing staff with higher levels of education (ranging from $84 \%$ for clinical assessment to $100 \%$ for mental health treatment and both substance use and mental health treatment).

\section{Behavioral health agencies}

Use of EBPs was more comprehensive in the affiliated BH agencies. With the exception of prevention services, nearly all $\mathrm{BH}$ agencies that provided screening, assessment, and 
treatment services used EBPs with at least half the youth in their programs. Similarly, agencies that reported using EBPs for screening assessment, prevention, and treatment reported these services were delivered almost always by clinical staff with higher levels of education.

\section{Interactions across CS agencies and BH service providers Cross-system collaborative activities}

Collaborative activities between CS agencies and BH service providers within JJ systems of care are displayed in Fig. 2. Nearly all CS agencies and BH providers reported that they did indeed have cross-system collaborations; most commonly they reported sharing information on client needs (100\% and $92 \%$, respectively). A majority of both $\mathrm{CS}$ agencies and $\mathrm{BH}$ service providers also reported having joint staffings/case reporting $(89 \%$ and $65 \%$, respectively) and written protocols for sharing information on clients (56\% and $74 \%$, respectively). Although $69 \%$ of CS agencies stated there was agreement on requirements for program eligibility, only $44 \%$ of the $\mathrm{BH}$ service providers concurred with this statement. Fewer than half of the affiliated $\mathrm{CS}$ and $\mathrm{BH}$ providers reported that they cross-train staff, modify some protocols to meet service partner needs, provide office space, have pooled funding to provide services, share operational oversight, have developed joint policy and procedure manuals, or share budgetary oversight. Overall, the $\mathrm{CS}$ agencies and $\mathrm{BH}$ service providers endorsed an average of $44 \%$ and $38 \%$, respectively, of the collaborative activities.

\section{Activities CS agencies routinely complete to facilitate referrals}

Among CS agencies, the most common referral practices reported to facilitate linkages with $\mathrm{BH}$ providers (regarding either substance use or mental health referrals) were speaking with a family member or caregiver to ensure that youth attended their appointments (99\%), checking on youth progress (98\%), and providing the caregivers with contact information for the service providers (96\%) (See Fig. 3). A large majority of CS agencies also

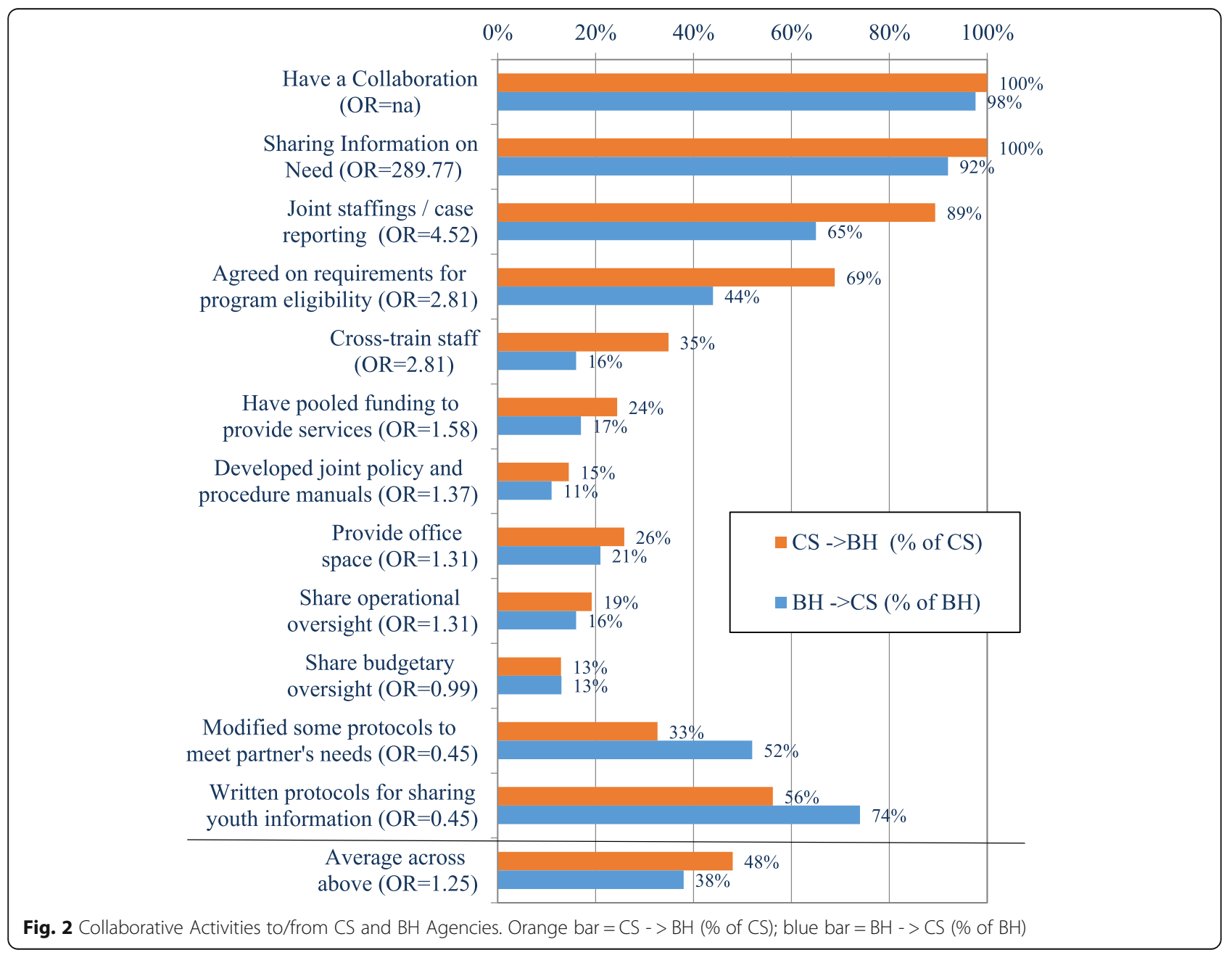




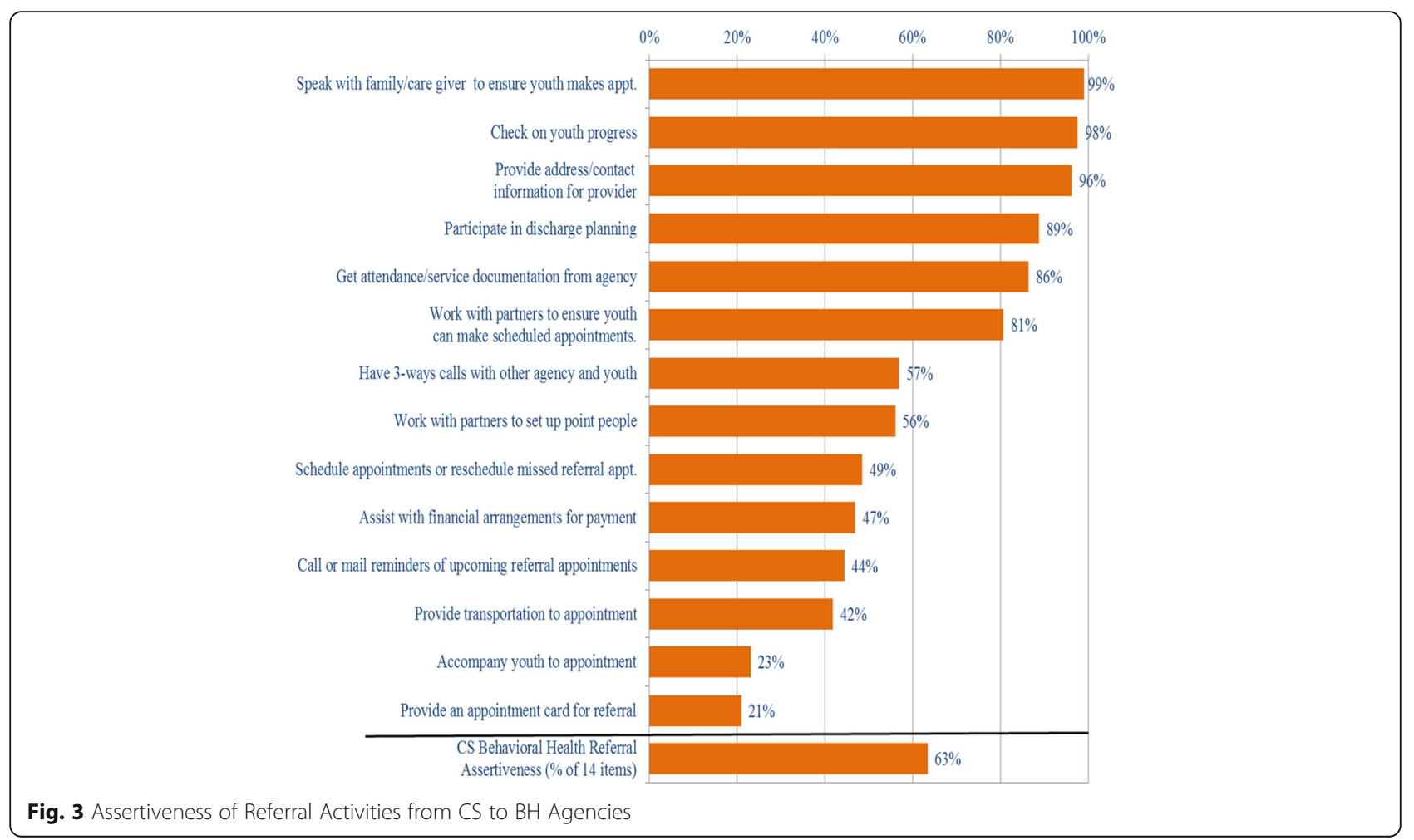

reported that they participate in discharge planning (89\%), obtain attendance/service document from the partner agency (86\%), work with service partners to ensure that youth were able to attend scheduled appointments $(81 \%)$, have 3-way calls with the other agency and the youth (57\%), and work with service partners to set up point people to coordinate care for the youth being referred (56\%). Fewer than half of the CS agencies reported that they schedule appointments or reschedule missed appointments (49\%), assist with financial arrangements for payment, provide appointment reminders (47\%), arrange for transportation to an appointment (42\%), accompany the youth to appointments $(23 \%)$, or provide the youth with appointment cards (21\%). Overall, the CS programs endorsed an average of $63 \%$ of the 14 items that facilitate referral.

\section{Services-related information transmitted from $\mathrm{BH}$ service providers Back to CS agencies}

The percentage of youth for whom information is transmitted from BH to CS, and conversely, is received by CS from BH is shown in Fig. 4. Information is most commonly transmitted from $\mathrm{BH}$ to $\mathrm{CS}$ programs regarding dates of admission and discharge, a discharge summary report, monthly or more frequent progress reports, dates of missed appointments, and discharge status. In contrast, information on urine or other biological tests and the amount of services received by the youth is less often sent from $\mathrm{BH}$ service providers to the CS agencies.
On average, $\mathrm{BH}$ programs provide information to $\mathrm{CS}$ agencies on about half (52\%) of the youth they serve, and similarly, CS agencies report receiving information from $\mathrm{BH}$ providers on about half (47\%) of the youth they serve.

\section{Comparisons across $\mathrm{CS}$ and $\mathrm{BH}$ collaboration groups}

In order to evaluate the JJ systems of care, composite indices were created on which affiliated CS agencies and BH service providers were classified separately as "high" or "low" on each of the following scales: (1) CS Referral Assertiveness, (2) CS Information Received from BH, (3) CS Quality of Direct BH Services (e.g., use of EBP), (4) $B H$ Information Sent to CS, and (5) BH Quality of Direct $B H$ Services. Table 4 shows the four high/low classification groups (in columns) by each of these five measures (in rows) with the mean \% of items endorsed in the cells. Differences across the four CS-BH collaboration groups formed based on a median split of the average percentage of items endorsed on each collaboration scale were examined using generalized linear model (GLM) analysis and model fit was evaluated with, probability of alpha, Cohen's $f$ index, and eta square.

The four groups explained 39\% of the variance in the joint distribution of these measures of collaboration. In particular, there were significant effects on CS Referral Assertiveness (Cohen's $\mathrm{f}=0.57$ ) and CS Information Received $(\mathrm{f}=0.36)$, and trends (Cohen's effect size $>0.10$ ) for the other 3 measures. The percent of items endorsed 


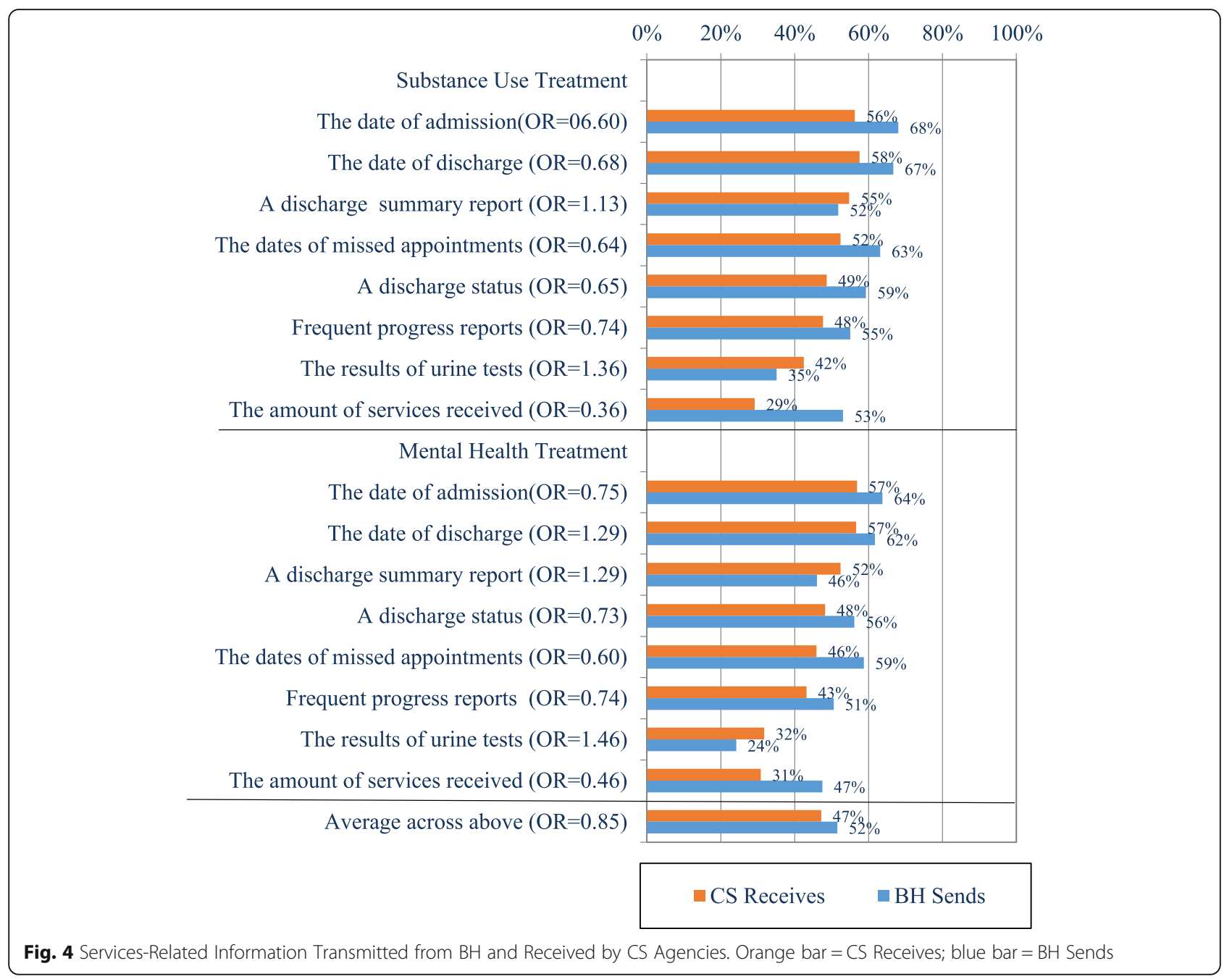

was in general highest for the $\mathrm{CS}$ high/ $\mathrm{BH}$ high followed by CS high/BH low (which was strong on CS Referral Assertiveness, CS Quality of Direct BH Service, and BH Information Sent to CS), CS low/BH low (which was still strong on CS Information Received from $B H$ ), and CS low/ BH high (which was only above average on the BH Quality of Direct BH Services).

\section{Discussion}

This study examined BH-need profiles of JJ-involved youth on CS, services provided and referred, use of EBPs, and collaborative activities across a representative national sample of CS agencies and their affiliated $\mathrm{BH}$ service providers within local JJ systems of care. The study utilized a parallel instrument across providers in the two service systems and analyzed findings by anchoring the $\mathrm{BH}$ providers to the corresponding CS agency within local systems (e.g., mainly counties) in order to derive weighted national estimates of systemlevel CS and BH providers. Prior studies have documented gaps in mental health services available for youth in juvenile detention centers, but have not examined cross-system referral and service provision (Osterlind et al. 2007; Pajer et al. 2007). The current study advances our understanding of the degree to which the services cascade is implemented across $\mathrm{CS}$ and $\mathrm{BH}$ providers, and areas that remain to be addressed in order to strengthen collaboration and improve service delivery across these systems.

As would be expected, the characteristics of youth served within the CS programs and their corresponding $\mathrm{BH}$ providers are similar demographically, although $\mathrm{BH}$ providers serve a more severe sub-group of JJ-involved youth, with a higher reported prevalence of $\mathrm{BH}$ problems. It is important to note that data availability was far from comprehensive in both systems, although a greater proportion of $\mathrm{BH}$ providers reported data for all types of $\mathrm{BH}$ problems. The greater availability of prevalence data in $\mathrm{BH}$ programs may reflect the fact that most CS programs screened and referred youth to $\mathrm{BH}$ providers for clinical assessments, a practice that is congruent with the survey findings that there is a greater availability of 
more highly trained clinical staff within $\mathrm{BH}$ programs that use EBP clinical assessments. Thus, although still not universal, the survey findings showed that $\mathrm{BH}$ screening and assessment is well established through linkages between $\mathrm{CS}$ and $\mathrm{BH}$ providers in most jurisdictions.

Overall, substance use prevention services are directly provided by few CS programs and by only slightly over half of $\mathrm{BH}$ programs. Further, among those programs that provided prevention services, only a minority utilized EBPs, and rarely were they offered to a majority of the youth served. This contrasts with a prior analysis of JJ-TRIALS survey data showing that most staff in JJ programs rated substance use prevention services as very important and congruent with their agency's mission (Sales et al., 2018). Clearly, expansion of substance use prevention services is warranted in both $\mathrm{CS}$ and $\mathrm{BH}$ programs, given the opportunities for intervening with this highrisk population. In addition, most $\mathrm{CS}$ and $\mathrm{BH}$ agencies relied upon referral to external providers for HIV and other infectious diseases prevention services, and use of EBPs for screening and prevention of HIV was rare. Yet, compared with their non-criminally involved counterparts, J-involved youth are at greater risk of HIV/STIs due to their risky sexual and drug-use behaviors (Teplin et al. 2003). Moreover, African American and Latino JJ-involved youth are disproportionally represented among the newly diagnosed with HIV. Given this need, it is critical that existing EBPs for HIV/STI prevention are adapted for JJ-involved youth and more widely implemented in these settings.

Improving the delivery of evidence-based $\mathrm{BH}$ services is acknowledged as a critical component within a rehabilitative orientation to juvenile justice (Thomas et al. 2005; McCord et al. 2001). The JJ-TRIALS surveys demonstrated that there were inverse relationships between the $\mathrm{CS}$ and $\mathrm{BH}$ systems, indicating that cross-system treatment referral for delivery of $\mathrm{BH}$ services has been broadly adopted across these service systems. A majority of CS programs reported use of EBPs to screen youth for $\mathrm{BH}$ problems. Direct provision of $\mathrm{BH}$ treatment was rare within CS programs; instead, a majority of CS programs referred youth to $\mathrm{BH}$ providers for substance use and/or mental health treatment. This approach is consistent with current policy initiatives that emphasize the broader system-of-care for delivery of BH services to JJinvolved youth, given the limited capacity of the JJS to respond to the complex $\mathrm{BH}$ needs of this population (Odgers et al. 2005).

Outpatient substance use treatment was most commonly provided in both systems, with less access to more intensive forms of substance use treatment (e.g., intensive outpatient, residential, medication-assisted treatment).
Similarly, individual and family counseling was widely available within $\mathrm{BH}$ programs, although more intensive forms of mental health treatment were either unavailable or unknown among one-fifth of the combined providers. The sparse availability of more intensive $\mathrm{BH}$ treatment suggests high risk for relapse and recidivism for youth with severe substance use and mental health problems, who are most likely to have persistent $\mathrm{BH}$ problems that lead to repeated cycles of criminal justice system contact (Ramchand et al., 2009; Schubert et al. 2011).

With regard to aftercare services, few JJ systems of care provided recovery support services to youth, with most relying upon external referrals for this service. One-fifth stated that recovery support for JJ-involved youth in their county was either unavailable or unknown. Although a majority of $\mathrm{BH}$ providers directly provided continuing or aftercare services, one quarter referred elsewhere for these services, and in 10\% of jurisdictions these services were unavailable or unknown to the providers. Both recovery support and continuing care are critical components for reducing relapse to substance use problems and recidivism among youth who have been involved in the JJ system (National Institute on Drug Abuse, 2014). The lack of access to these services within JJ systems of care indicates a risk of attrition of youth from the services cascade. Innovative models for delivery of recovery support services for youth include mHealth interventions using text-messaging prompts and supportive messages, which have shown promising outcomes with youth in substance use treatment (Dennis et al. 2015; Gonzales et al., 2014) and primary care (Shrier et al., 2018). Incorporating these interventions within $\mathrm{BH}$ services for JJ-involved youth may be especially warranted.

Consistent with the cascade model of service delivery to JJ-involved offenders, the findings suggest that many $\mathrm{CS}$ and $\mathrm{BH}$ providers have established mechanisms for referral, information exchange, and collaboration. One quarter of the paired CS and $\mathrm{BH}$ provider groups were classified as both "high" on indices of cross-system interactions and quality of services provision. However, close to two fifths of the paired CS-BH providers were classified as "low" on both the indices of cross-system interactions and quality of services provision, with the remainder falling into mixed classifications of high/low. It is noteworthy that the two groups with "high" CS ratings on collaboration and interactions (with $\mathrm{BH}$ either high or low), had the highest overall collaboration scores, demonstrating the value of CS leadership in these relationships. Other research examining the provision of $\mathrm{BH}$ services for youth involved in both the JJ and child welfare systems found that having a single agency accountable for youth care, along with inter-agency sharing of administrative data, increased the odds of youth receiving BH services (Chuang \& Wells, 2010). Others 
have argued that a holistic understanding of youth's social/environmental context and the involvement of families and community services are needed to minimize the adoption of "system-centric" approaches to assessing the needs of youth, which lead to a skewed understanding of their service needs (Maschi et al. 2008). Hence, efforts aimed at improving $\mathrm{BH}$ services provision to JJ-involved youth require both strong CS leadership and the adoption of a multisystemic approach to understanding and meeting their needs.

\section{Limitations}

Several limitations of the study should be acknowledged. For example, many programs did not have access to information on the $\mathrm{BH}$ needs of youth they served, and among those that had such information, there was a wide range of measures and definitions used to assess $\mathrm{BH}$ status and needs. The current study included no internal measures to identify the background, knowledge, training, and other characteristics of respondents as well as the quality and validity of the clinical assessments. Admittedly, indices of cross-system interactions and quality of BH services relied on crude counts of activities performed, although we note that these measures met standards for internal validity.

\section{Conclusion}

Despite these limitations, the study findings provide a barometer for progress in developing $\mathrm{BH}$ systems of care for JJ-involved youth, identifying gaps within these service systems, and highlighting areas where improvements are urgently needed. The findings show that although many elements in a cascade model of $\mathrm{BH}$ services for JJ-involved youth have been implemented through cross-system referrals and collaboration between $\mathrm{CS}$ and $\mathrm{BH}$ providers, there are several underdeveloped areas and potential for attrition across the service cascade. In particular, greater attention is needed to providing services that address the needs of youth with higher levels of severity, aftercare services, and recovery support. Future research should aim to develop interventions to address these identified gaps within JJ systems of care, as well as examine the relationship between systems-of-care characteristics and youth outcomes, such as recidivism.

\section{Additional file}

Additional file 1: "Sources for JJ-TRIALS survey items," provides a list of all sources for items used in the JJ-TRIALS national survey. (DOCX $29 \mathrm{~kb}$ )

\section{Abbreviations}

BH: Behavioral health; CS: Community supervision; EBP: Evidence-based practice; FTE: Full-time equivalents; HIV: Human immunodeficiency virus; JJ: Juvenile justice; JJS: Juvenile justice system; JJ-TRIALS: Juvenile Justice-
Translational Research on Interventions for Adolescents in the Legal System; OR: Odds ratio; STIs: Sexually transmitted infections

\section{Acknowledgements}

The authors thank Kelli Wright and Brittany Moody for their assistance in preparing the manuscript; Susan Godley for her helpful comments on the paper; Bruce Spenser for his invaluable assistance developing the sampling and weighting strategies; the JJ-TRIALS Survey Advisory Board (Nancy Arrigona, Patrick Flynn, Craig E. Henderson, Matt Hiller, Hannah K. Knudsen, Mark W. Lipsey, Edward (Ned) Loughran, Shawn Marsh, David Morse, Anne Spaulding, Faye Taxman, Gail Wasserman, Carl Wicklund, and Tisha Wiley) for input on the survey and design; the staff who worked on the project; and most of all, the respondents for completing the surveys.

\section{Authors' contributions}

CKS: designed the study, conceptualized the manuscript, co-wrote initial manuscripts, MLD: designed survey sample methodology, oversaw data analyses, co-wrote initial manuscripts. CEG: contributed to conceptualizing and writing the manuscript. RF: provided input on statistical design and measurement, conducted statistical analyses. AFL: provided input into conceptualizing and writing the manuscript. All authors read and approved the final manuscript.

\section{Authors' information}

- Christy K. Scott, Ph.D., is the Director of the Lighthouse Institute and the Illinois Survey Laboratory at Chestnut Health Systems, Chicago, IL. Her research focuses on understanding and predicting how people move through the cycles of substance use, crime, treatment, incarceration, and periods of recovery, as well as how to experimentally test strategies for improving recovery management over time. Publishing widely on recovery management, how to achieve greater than 90\% follow-up rates in longitudinal studies, and intensive data collection with smart phones, she has developed and tested different interventions for managing addiction over time.

- Michael L. Dennis, Ph.D., is a Senior Research Psychologist at the Lighthouse Institute and Director of the GAIN Coordinating Center at Chestnut Health Systems, Normal, IL. His research focus is understanding and predicting how people move through the cycles of substance abuse, crime, treatment, incarceration, and periods of recovery, as well as how to experimentally test strategies for improving recovery management over time. He has published widely on recovery management, integrating clinical and research assessment, measurement, intensive data collection with smart phones, and evaluation research.

- Christine E. Grella, Ph.D., has a joint appointment as a Senior Research Scientist at Chestnut Health Systems and a Professor-in-Residence in the Department of Psychiatry and Biobehavioral Sciences at University of California, Los Angeles (UCLA) and co-director of the UCLA Integrated Substance Abuse Programs. Her research focuses on the intersection of multiple service delivery systems, including substance abuse treatment, mental health, child welfare, health services, HIV services, and criminal justice, and the relationship of service delivery with treatment outcomes. She has published her work widely in the areas of addiction, mental health, health services, and evaluation research.

- Rodney R. Funk is a Research Associate at the Lighthouse Institute of Chestnut Health Systems in Normal, IL. He holds SPSS's highest certification for data mining methods and modeling. His research interests are in the analysis of complex hierarchical and intensive data analytic models, as well as using clustering techniques to interpret heterogeneous samples and trends over time.

- Arthur J. Lurigio, Ph.D., psychologist, is the Senior Associate Dean for faculty in the College of Arts and Sciences and a Professor of Criminal Justice and Criminology and Psychology, Loyola University Chicago. Named a 2003 Faculty Scholar, the highest honor bestowed on senior faculty at Loyola, he was named a Master Researcher in 2013 by the College of Arts and Sciences in recognition of his continued scholarly productivity. 


\section{Funding}

This article was supported by National Institute on Drug Abuse (NIDA) Grant no. U01DA036221. The opinions expressed here, however, are those of the authors and do not represent official positions of the government.

\section{Availability of data and materials}

The datasets used and/or analyzed during the current study are available from the corresponding author on reasonable request.

\section{Ethics approval and consent to participate}

The study was conducted under the supervision of Chestnut Health Systems' Institutional Review Board (IRB) for the protection of human subjects (IRB Research Study No. 1090-1213). Participation in the study was voluntary and participants could choose not to answer any question without consequences.

\section{Consent for publication}

Not applicable as no individual respondents identified.

\section{Competing interests}

The authors declare that they have no competing interests.

\section{Author details}

${ }^{1}$ Chestnut Health Systems, 221 W. Walton St., Chicago, IL 60610, USA. ${ }^{2}$ Loyola University Chicago, Chicago, USA.

\section{Received: 19 March 2019 Accepted: 22 May 2019}

\section{Published online: 14 June 2019}

\section{References}

Abram, K. M., Choe, J. Y., Washburn, J. J., Teplin, L. A., King, D. C., \& Dulcan, M. K. (2008). Suicidal ideation and behaviors among youths in juvenile detention. Journal of the American Academy of Child \& Adolescent Psychiatry, 47(3), 291-300.

Abram, K. M., Teplin, L. A., Charles, D. R., Longworth, S. L., McClelland, G. M., \& Dulcan, M. K. (2004). Posttraumatic stress disorder and trauma in youth in juvenile detention. Archives of General Psychiatry, 61(4), 403-410.

Abram, K. M., Teplin, L. A., McClelland, G. M., \& Dulcan, M. K. (2003). Comorbid psychiatric disorders in youth in juvenile detention. Archives of General Psychiatry, 60, 1097-1108.

Abram, K. M., Washburn, J. J., Teplin, L. A., Emanuel, K. M., Romero, E. G., \& McClelland, G. M. (2007). Posttraumatic stress disorder and psychiatric comorbidity among detained youths. Psychiatric Services, 58, 1311-1316.

Abram, K. M., Zwecker, N. A., Welty, L. J., Hershfield, J. A., Dulcan, M. K., \& Teplin, L. A. (2015). Comorbidity and continuity of psychiatric disorders in youth after detention: A prospective longitudinal study. JAMA Psychiatry, 72(1), 84-93.

Belenko, S., Knight, D., Wasserman, G. A., Dennis, M. L., Wiley, T., Taxman, F. S., Oser, C., Dembo, R., Robertson, A. A., \& Sales, J. (2017). The juvenile justice behavioral health services cascade: A new framework for measuring unmet substance use treatment services needs among adolescent offenders. Journal of Substance Abuse Treatment, 74, 80-91.

Champion, D. J. (2001). The juvenile justice system: Delinquency, processing, and the law. Upper Saddle River, NJ: Prentice-Hall.

Chapman, J. F., \& Ford, J. D. (2008). Relationships between suicide risk, traumatic experiences, and substance use among juvenile detainees. Archives of Suicide Research, 12(1), 50-61

Chuang, E., \& Wells, R. (2010). The role of inter-agency collaboration in facilitating receipt of behavioral health services for youth involved with child welfare and juvenile justice. Children and Youth Services Review, 32(12), 1814-1822.

Cocozza, J. J., Skowyra, K. R., \& Shufelt, J. L. (2010). Addressing the mental health needs of youth in contact with the juvenile justice system in system of care communities: An overview and summary of key issues. Washington, DC Technical Assistance Partnership for Child and Family Mental Health.

D'Amico, E. J., Edelen, M. O., Miles, J. N., \& Morral, A. R. (2008). The longitudinal association between substance use and delinquency among high-risk youth. Drug and Alcohol Dependence, 93(1-2), 85-92.

Dennis, M. L., Scott, C. K., Funk, R. R., \& Nicholson, L. (2015). A pilot study to examine the feasibility and potential effectiveness of using smartphones to provide recovery support for adolescents. Substance Abuse, 36(4), 486-492.

Dennis, M. L., White, M. K., \& Ives, M. L. (2009). In C. G. Leukefeld, T. P. Gullotta, \& M. Staton-Tindall (Eds.), Issues in children's and families' lives. Adolescent substance abuse: Evidence-based approaches to prevention and treatment Individual characteristics and needs associated with substance misuse of adolescents and young adults in addiction treatment (pp. 45-72). New York, NY: Springer Science + Business Media.

Donenberg, G. R., Emerson, E., Mackesy-Amiti, M. E., \& Udell, W. (2015). HIV-risk with juvenile offenders on probation. Journal of Child and Family Studies, 24(6), 1672-1684.

Epperson, M., Wolff, N., Morgan, R., Fisher, W., Frueh, B. C., \& Huening, J. (2011). The next generation of behavioral health and criminal justice interventions: Improving outcomes by improving interventions. New Brunswick, NJ: Center for Behavioral Health Services and Criminal Justice Research, Rutgers. In The State University of new Jersey.

Ford, J. D., Elhai, J. D., Connor, D. F., \& Frueh, B. C. (2010). Polyvictimization and risk of posttraumatic, depressive, and substance use disorders and involvement in delinquency in a national sample of adolescents. Journal of Adolescent Health, 46(6), 545-552.

Ford, J. D., Grasso, D. J., Hawke, J., \& Chapman, J. F. (2013). Poly-victimization among juvenile justice-involved youths. Child Abuse and Neglect, 37(10), 788-800.

Gonzales, R., Ang, A., Murphy, D. A., Gilk, D. C., \& Anglin, D. A. (2014). Substance use recovery outcomes among a cohort of youth participating in a mobilebased texting aftercare pilot program. Journal of Substance Abuse Treatment, 47(1), 20-26.

Grisso, T. (2004). Double jeopardy: Adolescent offenders with mental disorders. Chicago, IL: University of Chicago Press.

Grisso, T., \& Underwood, L. A. (2004). Screening and assessing mental health and substance use disorders among youth in the juvenile justice system. Washington, DC: Office of Juvenile Justice and Delinquency Prevention.

Howell, J. C., Kelly, M. R., Palmer, J., \& Mangum, R. L. (2004). Integrating child welfare, juvenile justice, and other agencies in a continuum of services. Child Welfare, 83(2), 143-156

Huizinga, D., Loeber, R., Thornberry, T., \& Cothern, L. (2000). Co-occurrence of delinquency and other problem behaviors. Washington, DC: Office of Juvenile Justice and Delinquency Prevention.

Ives, M. L., Chan, Y., Modisette, K. C., \& Dennis, M. L. (2010). Characteristics, needs, services, and outcomes of youth in juvenile treatment drug courts as compared to adolescent outpatient treatment. Drug Court Review, 7(1), 10-56.

Kaeble, D., \& Glaze, L. E. (2016). Correctional populations in the United States (p. 2015). Washington, DC: Bureau of Justice Statistics.

Karnik, N. S., Soller, M., Redlich, A., Silverman, M., Kraemer, H. C., Haapanen, R., \& Steiner, H. (2009). Prevalence of and gender differences in psychiatric disorders among juvenile delinquents incarcerated for nine months. Psychiatric Services, 60(6), 838-841.

King, D. C., Abram, K. M., Romero, E. G., Washburn, J. J., Welty, L. J., \& Teplin, L. A. (2011). Childhood maltreatment and psychiatric disorders among detained youths. Psychiatric Services, 62(12), 1430-1438.

Lansing, A. E., Washburn, J. J., Abram, K. M., Thomas, U. C., Welty, L. J., \& Teplin, L. A. (2014). Cognitive and academic functioning of juvenile detainees: Implications for correctional populations and public health. Journal of Correctional Health Care, 20(1), 18-30.

Lehman, B. W. F. (2009). H.K., Wexler, G., \& Melnick. Organizational factors and collaboration and integration activities in criminal justice and drug abuse treatment agencies. Drug and Alcohol Dependence, 103(Supl. 1), S65-S72.

Lipsey, M. W. (2009). The primary factors that characterize effective interventions with juvenile offenders: A meta-analytic review. Victims and Offenders, 4(1), 124-147.

Maschi, T., Hatcher, S. S., Schwalbe, C. S., \& Rosato, N. S. (2008). Mapping the social service pathways of youth to and through the juvenile justice system: A comprehensive review. Children and Youth Services Review, 30(12), 13761385.

McCarty, D., \& Chandler, R. K. (2009). Understanding the importance of organizational and system variables on addiction treatment services within criminal justice settings. Drug and Alcohol Dependence, 103(Suppl 1), S91-S93.

McCord, J., Widom, C. S., \& Crowell, N. A. (Eds.). (2001). Juvenile crime, juvenile justice. Washington, DC: National Academy Press.

Mendel, R.A. (2011). No place for kids: The case of reducing juvenile incarceration. Baltimore, MD: The Annie E. Casey Foundation.

National Institute on Drug Abuse. (2014). Principles of adolescent substance use disorder treatment: A research-based quide. (NIH Publication No. 14-7953). Bethesda, MD: National Institute on Drug Abuse. 
Odgers, C. L., Burnette, M. L., Chauhan, P., Moretti, M. M., \& Reppucci, N. D. (2005). Misdiagnosing the problem: Mental health profiles of incarcerated juveniles. Canadian Child and Adolescent Psychiatry Review, 14, 26-29.

Osterlind, S. J., Koller, J. R., \& Morris, E. F. (2007). Incidence and practical issues of mental health for school aged youth in juvenile justice detention. Journal of Correctional Health Care, 13, 268-277.

Pajer, K. A., Kelleher, K., Gupta, R. A., Rolls, J., \& Gardner, W. (2007). Psychiatric and mental health care policies in juvenile detention facilities. Journal of the American Academy of Child and Adolescent Psychiatry, 46, 1660-1667.

Ramchand, R., Morral, A. R., \& Becker, K. (2009). Seven-year life outcomes adolescent offenders in Los Angeles. American Journal of Public Health, 99(5), 863-870.

Romero, E. G., Teplin, L. A., McClelland, G. M., Abram, K. M., Welty, L. J., \& Washburn, J. J. (2007). A longitudinal study of the prevalence, development, and persistence of HIV/sexually transmitted infection risk behaviors in delinquent youth: Implications for health care in the community. Pediatrics, 119(5), e1126-e1141.

Sales, J. M., Wasserman, G., Elkington, K. S., Lehman, W., Gardner, S., McReynolds, L., Wiley, T., \& Knudsen, H. (2018). Perceived importance of substance use prevention in juvenile justice: A multi-level analysis. Health and Justice, 6(1), 12

Schubert, C., \& Mulvey, E. P. (2014). Behavioral health problems, treatment, and outcomes in serious youthful offenders. In Juvenile Justice Bulletin. Washington, DC: Office of Juvenile Justice and Delinquency Prevention.

Schubert, C., Mulvey, E. P., \& Glasheen, C. (2011). Influence of mental health and substance abuse problems and criminogenic risk on outcomes in serious juvenile offenders. Journal of the American Academy of Child and Adolescent Psychiatry, 50, 925-937.

Scott, C. K., Lurigio, A. J., \& Dennis, M. L. (2017). Judges' perceptions of screening, assessment, prevention, and treatment for substance use, mental health, and HIV among juveniles on community supervision: Results of a national survey. Juvenile and Family Court Journal, 68(3), 5-25.

Shrier, L. A., Burke, P. J., Kells, M., Scherer, E. A., Sarda, V., Jonestrask, C., Xuan, Z., \& Harris, S. K. (2018). Pilot randomized trial of MOMENT, a motivational counseling-plus-ecological momentary intervention to reduce marijuana use in youth. mHealth, 4, 29 .

Shufelt, J. L., \& Cocozza, J. (2006). Youth with mental health disorders in the juvenile justice system: Results from a multi-state prevalence study. Delmar, NY: National Center for Mental Health and Juvenile Justice.

Tapia, M., McCoy, H., \& Tucker, L. (2016). Suicidal ideation in juvenile arrestees: Exploring legal and temporal factors. Youth Violence and Juvenile Justice, 14(4), 468-483.

Teplin, L. A., Abram, K. M., McClelland, G. M., Dulcan, M. K., \& Mericle, A. A. (2002). Psychiatric disorders in youth in juvenile detention. Archives of General Psychiatry, 59, 1133-1143

Teplin, L. A., Mericle, A. A., McClelland, G. M., \& Abram, K. M. (2003). HIV and AIDS risk behaviors in juvenile detainees: Implications for public health policy. American Journal of Public Health, 93, 906-912.

Teplin, L. A., Stokes, M. L., McCoy, K. P., Abram, K. M., \& Byck, G. R. (2015). Suicidal ideation and behavior in youth in the juvenile justice system: A review of the literature. Journal of Correctional Health Care, 21(3), 222-242.

Thomas, J., Gourley, G. K., \& Mele, N. (2005). The availability of behavioral health services for youth in the juvenile justice system. Journal of the American Psychiatric Nurses Association, 11, 156-163.

Timmons-Mitchell, J., Brown, C., Schulz, S., Webster, S., Underwood, L., \& Semple, W. (1997). Comparing the mental health needs of female and male incarcerated juvenile delinquents. Behavioral Sciences \& the Law, 15, 195-202.

Tolou-Shams, M., Stewart, A., Fasciano, J., \& Brown, L. K. (2009). A review of HIV prevention interventions for juvenile offenders. Journal of Pediatric Psychology, 35(3), 250-261.

Trupin, E., \& Boesky, L. (1999). Working together for change: Co-occurring mental health and substance use disorders among youth involved in the juvenile justice system: Cross training, juvenile justice, mental health, and substance abuse. Delmar, NY: The National GAINS Center.

Underwood, L. A., \& Washington, A. (2016). Mental illness and juvenile offenders. International Journal of Environmental Research and Public Health, 13, 228.

United States Census. (2012). 2010 Current Population Survey (CPS) Data File. https://www.census.gov/programs-surveys/cps.html. Accessed 8 February 2018.
Wasserman, G. A., McReynolds, L. S., Lucas, C. P., Fisher, P., \& Santos, L. (2002). The voice DISC-IV with incarcerated male youths: Prevalence of disorder. Journal of the American Academy of Child and Adolescent Psychiatry, 41, 314-321.

Young, D. W., Dembo, R., \& Henderson, C. E. (2007). A national survey of substance abuse treatment for juvenile offenders. Journal of Substance Abuse Treatment, 32(3), 255-266.

\section{Publisher's Note}

Springer Nature remains neutral with regard to jurisdictional claims in published maps and institutional affiliations.
Ready to submit your research? Choose BMC and benefit from:

- fast, convenient online submission

- thorough peer review by experienced researchers in your field

- rapid publication on acceptance

- support for research data, including large and complex data types

- gold Open Access which fosters wider collaboration and increased citations

- maximum visibility for your research: over $100 \mathrm{M}$ website views per year

At $\mathrm{BMC}$, research is always in progress.

Learn more biomedcentral.com/submissions 